\title{
EDITORIAL
}

\section{GUIDING DRUG DISCOVERY THROUGH 2003}

\author{
With the fall in the numbers of new drugs reaching crisis point, there has never been a better \\ time to stop and consider how best to run the drug pipeline. This year we launch two new \\ sections with the aim of helping us to understand the craft of drug discovery.
}

The miserable tally of new drug approvals in 2002 (at the time of writing, just 15 new molecular entities had passed FDA review), well down even on the depressingly low average for the last five years (31 a year), shows just how rare an event success can be in the drug discovery world. And with new drug application numbers down worldwide, concern is beginning to spread beyond the borders of the pharmaceutical industry. Last month, the European Parliament's Environment Committee summoned Thomas Lönngren, Executive Director of the European Agency for the Evaluation of Medicinal Products (EMEA), to come and explain the fall in the numbers of applications. Faced with sparsely populated pipelines, companies are beginning to shift research budgets towards more aggressive marketing of existing products. These are worrying times.

The high failure rate is not that surprising, when one calls to mind how many different variables have to fit together in just the right combination in order to bring a drug to launch. Chemistry, pharmacology, toxicology and physiology all have to be spot on - to say nothing of the reception a new product receives in the market. Understanding the lengthy process of turning ideas into drugs is universally acknowledged as being the hardest skill to teach new recruits to the drug discovery business. So, for 2003 , we are adding two new didactic elements to the journal: a series of monthly articles giving readers a step-by-step guide to the craft of drug discovery and development, and a new section analysing the science and market behind recently launched drugs.

The new 'Guide to Drug Discovery', a series of 12 articles launching this month with an overview of 'Target selection' by Jonathan Knowles and Gianni Gromo, will provide a manual for the evolving world of drug discovery and development. The articles aim to oil the wheels of drug discovery by giving a broad and highly accessible overview of the drug pipeline, allowing readers with limited previous knowledge of any area to become familiar with the key concepts and techniques involved, as well as the future directions an area might move in. We might subtitle these articles 'All you always wanted to know about XXX, but were afraid to ask', and we hope that the insight they will lend to the workings of the pipeline will facilitate the interdisciplinary interaction that we believe is becoming an increasingly important part of the business of discovering and developing drugs.

Linked with each of the 'Guide' articles, our 'Careers Focus' section for 2003 will cover a related discipline each month. Knowles and Gromo highlight the increasingly important role that forecasting is playing in target decisions, once seen more as the preserve of scientists alone. In his 'Careers Focus' article, John Earl discusses the attributes of a typical market forecaster and gives examples of the myriad variables that they contend with on a daily basis.

'Fresh from the pipeline', our other new addition, builds on our series of 'Case history' and 'From the analyst's couch' articles by considering the outlook for an important newly launched drug each month. Explaining the science on one page, and the market outlook on another, these short snapshots aim to summarize all the essential information about each drug in just two pages. They will also allow us to explore some of the factors controlling the market dynamics following a new launch. This month's article on Xigris, the new sepsis treatment from Eli Lilly, asks why, a year after its launch in the United States, the drug has failed to meet everyone's expectations. Looking back over past examples suggests, however, that such a gradual market uptake might, in the end, result in a more sustained market presence for Xigris than if it had erupted onto the market as the 'blockbuster' it was forecast to be. Over the coming months, 'Fresh from the pipeline' should build into a reference manual of brief case studies, perhaps giving us the chance to learn from others' experience. 